\title{
Ability of IR and NMR Spectral Data to Distinguish between a Tetrel Bond and a Hydrogen Bond
}

\author{
Steve Scheiner* \\ Department of Chemistry and Biochemistry \\ Utah State University \\ Logan, UT 84322-0300
}

*email: steve.scheiner@usu.edu

phone: 435-797-7419

\begin{abstract}
The placement of a nucleophile $\mathrm{X}$ along the $\mathrm{R}-\mathrm{CH}_{3}$ axis of a methyl group can be described as either a trifurcated H-bond or as a tetrel bond between C and X. Quantum calculation of the vibrational and NMR spectral features of a number of systems are used to provide a framework by which to distinguish between the presence of a tetrel or H-bond. Both cationic and neutral methyl-containing Lewis acids $\left(\mathrm{SMe}_{3}^{+}, \mathrm{NMe}_{4}^{+}, \mathrm{SMe}_{2}\right.$ ) are paired with both neutral and anionic Lewis bases $\left(\mathrm{NH}_{3}, \mathrm{OH}_{2}, \mathrm{OCHNH}_{2}, \mathrm{OCH}_{3}^{-}, \mathrm{OH}^{-}, \mathrm{HCOO}^{-}\right)$. As the base is moved away from the $\mathrm{R}-\mathrm{CH}_{3}$ axis of the Lewis acid (tetrel bond) toward a position along a $\mathrm{CH}$ axis $(\mathrm{CH} \cdot \mathrm{X}$ H-bond), the methyl stretching frequencies shift to the red and the bending modes to the blue. This modification in the geometry also causes the methyl $\mathrm{C}$ atom NMR chemical shielding to increase, while the methyl $\mathrm{H}$ atom is progressively deshielded. These changes are of sufficiently large magnitude that they should provide a means to distinguish these two bonding situations from one another.
\end{abstract}




\section{INTRODUCTION}

In recent years, the concept of the H-bond (HB) has broadened as it has been learned that a variety of different atoms can replace the bridging $\mathrm{H}$ without loss of noncovalent bond strength. Perhaps surprisingly, these substitute atoms are drawn from some of the most electronegative portions of the periodic table ${ }^{1-6}$. Each noncovalent bond is typically named after the family of the bridging atom; halogen, chalcogen, and pnicogen bonds have all attracted a good deal of attention and have been increasingly well characterized. Like H-bonds, these too draw their strength from a combination of attractive electrostatic, polarization, charge transfer, and dispersion forces ${ }^{4,7-16}$.

A particularly interesting noncovalent bond is formed when the bridging atom is one of the tetrel $(\mathrm{C}, \mathrm{Si}, \mathrm{Ge}$, etc) family. These atoms are commonly covalently bonded to four groups, which offer a steric barrier of sorts for an incoming nucleophile/base, which must find its way to the central tetrel atom through this thicket of surrounding substituents. Nonetheless, tetrel bonds (TBs) do form despite this obstacle, sometimes distorting the geometry of the tetrel-bearing atom as necessary along the way. The term "tetrel bond" was first coined in $2013{ }^{17}$ where it was related to atoms below $\mathrm{C}$ in this family of the periodic table. And indeed it is to these heavier atoms that most previous work has been devoted ${ }^{18-26}$. In the case of the $\mathrm{C}$ atom, its ability to engage in a TB has typically been amplified by adding a number of electron-withdrawing substituents like $\mathrm{F}^{27-29}$ rather than considering a $\mathrm{CH}_{3}$ group itself. Our own lab has contributed to the current understanding of tetrel bonding as well ${ }^{30-35}$ including the issue of steric crowding ${ }^{26,36}$ and the manner in which such interactions might be used to design an effective selective anion receptor ${ }^{37-40}$. In sum, like their noncovalent bonding counterparts, TBs are strengthened by electron-withdrawing substituents whose polarization induces a more positively charged central atom. Like halogen, and related noncovalent bonds, all of these bonds are typically stronger for bridging atoms further down the column of the periodic table, facilitated by their more electropositive and polarizable natures. Indeed, atoms of the first row of the periodic table $(\mathrm{C}, \mathrm{N}, \mathrm{O}, \mathrm{F})$ are reluctant to engage in bonds of this sort.

All of which brings us to the case of the methyl group, one of the most common in all of chemistry and biochemistry. Due to the small size of the $\mathrm{C}$ atom, coupled with the presence of three non-electron withdrawing substituents, one would not expect the methyl group to readily engage in T-bonding. Yet thorough reviews of a variety of structures yield numerous interactions, on the order of thousands, where a powerful nucleophilic atom is poised in the precise position, near to the extension of the R-C bond axis, that is consistent with a TB ${ }^{41-44}$. There are also a number of proposals that it is just this sort of TB that is part and parcel of enzymatic activity ${ }^{45-}$ 49. However, structural studies are unable to deduce whether there is a truly attractive noncovalent bond present, or whether the two groups adopt their relative positions due to structural restraints in other parts of the system, with little or no attractive force between them. Again in the special case of the methyl group, the usual 
interpretation of a linear $\mathrm{R}-\mathrm{C} \cdots \mathrm{O}$ alignment involves a trifurcated $\mathrm{CH} \cdot \mathrm{O} \mathrm{H}$-bond, with the nucleophile engaging in three distorted nonlinear H-bonds with each of the methyl protons. However, this idea ignores the possibility of a $\mathrm{C} \cdot \mathrm{O}$ TB.

With specific regard to the methyl group, there have been a few studies of its possible tetrel bonding. Mani and Arunan showed that the placement of a $\mathrm{F}$ atom opposite the incoming nucleophile permits the $\mathrm{C}$ atom of $\mathrm{FCH}_{3}$ to engage directly in a TB ${ }^{50}$. Row's group ${ }^{41}$ soon thereafter identified more than 700 structures in the CSD that fit this notion of methyl groups participating in these sorts of bonds, and provided confirmation based on analyses of experimental charge density. Grabowski considered ${ }^{51}$ the methyl group in both $\mathrm{CH}_{4}$ and $\mathrm{FCH}_{3}$ and detected TBs, albeit rather weak ones, unless paired with an anionic nucleophile. The ability of $\pi$-electrons to serve as a nucleophile in a TB to $\mathrm{XCH}_{3}$ was examined ${ }^{52}$ and found to be possible but quite weak, while more negatively charged hydrides $(\mathrm{MH})^{53}$ are more effective in this regard. The $\mathrm{C}$ atoms of $\mathrm{C} \equiv \mathrm{N}-\mathrm{R}$ as also capable ${ }^{54}$ of engaging in a TB with a methyl group. Even stronger are the TBs to full-fledged anions ${ }^{55-56}$. Cooperative effects have been shown to amplify TBs to a certain degree ${ }^{57}$, when for example the nucleophile is intensified by itself engaging in another interaction with another nucleophile ${ }^{58}$. After noting that the nearly linear R-C $\cdot \mathrm{O}$ configuration is not uncommon in proteins, Bauzá and Frontera ${ }^{43}$ considered whether tetrel bonding is an appropriate designation, or might it be better categorized as a trifurcated H-bond, and concluded in favor of the former.

While a certain amount of information has accumulated in recent years concerning the ability of the methyl group to engage in a TB, there has been little in the way of comparison of this interaction to a $\mathrm{CH} \cdot \mathrm{X} \mathrm{H}^{-b o n d}$ in which this same group might participate. In most cases, only a pure T-bonding geometry was considered, or a linear $\mathrm{CH} \cdot \mathrm{O}$ configuration ${ }^{59-61}$, rather than the spectrum of structures that might arise in a protein wherein the nucleophile can adopt a position intermediate between the two extremes of a TB, with $\theta(\mathrm{R}-\mathrm{C} \cdot \mathrm{O})=180^{\circ}$, and a $\mathrm{HB}$ with a linear $\mathrm{CH}^{*} \mathrm{O}$ arrangement. And importantly, there is a real scarcity of information available as to how these two configurations, and those in between, would impact the spectroscopic parameters.

One might wonder whether the denoting of a linear $\mathrm{R}-\mathrm{CH}_{3} \cdots \mathrm{O}$ configuration as a tetrel or trifurcated H-bond is merely a philosophical issue with no real bearing, a difference without a distinction. How does the latter TB differ from a trifurcated HB? Do these two situations differ in terms of strength, in electronic structure, or mechanistically? And from a practical point of view, how is one to distinguish the two situations? Other than structural information emerging from diffraction data, the most common means of studying these sorts of interactions are spectroscopic. Both IR and NMR spectra are commonly used to identify HB. But there is little known about the spectral manifestations of a TB to a methyl group, and how this data might be used to distinguish this interaction from a HB. It is to this purpose that the present work brings quantum chemical calculations to bear. 


\section{SYSTEMS AND METHODS}

The systems examined are illustrated schematically in Fig 1. The Lewis acid was taken as $\mathrm{SMe}_{3}{ }^{+}$for several of these systems as the sulfonium group plays a crucial role in a number of methyl transferase enzymes wherein the interaction between its transferring methyl group and a nucleophile is a prime issue of current inquiry ${ }^{47,62-65}$. This cation is paired first with $\mathrm{NH}_{3}$ as a model of the $\mathrm{N}$-nucleophile to which this methyl transfers in some of these enzymes $46-47,66$, and secondly with $\mathrm{HOH}$ which models not only a water molecule itself but other hydroxyl-containing groups ${ }^{45}$. $\mathrm{OCH}_{3}{ }^{-}$was chosen as a representative anion so as to determine how the strong cation-anion interaction might change the spectroscopic parameters. Both $\mathrm{OH}^{-}$and $\mathrm{HCOO}^{-}$were chosen as anions that might interact with a neutral thioether $\mathrm{SMe}_{2}$. The former is present in basic solution and the latter serves as a model of glutamate and aspartate residues ${ }^{67}$. So as to broaden the scope to methyl groups attached to atoms other than $\mathrm{S}, \mathrm{NMe}_{4}{ }^{+}$was taken as an alternate methyl donor, pairing it with the peptide group model $\mathrm{HCONH}_{2}$. Indeed, a methyl group bonded to a $\mathrm{N}$ atom is a common tetrel-bonding unit as for example in the M3 muscarinic acetylcholine receptor bound to tiotropium ${ }^{68}$.

As indicated in Fig 1, R represents the distance separating the methyl $\mathrm{C}$ atom from the approaching nucleophilic atom, whether $\mathrm{N}$ or $\mathrm{O}$. The $\theta$ angle is equal to $180^{\circ}$ when the nucleophile lines up directly along the $\mathrm{S} / \mathrm{N}-\mathrm{C}$ axis, as would occur in a purely tetrel bond. A smaller value of $\theta$, roughly $110^{\circ}$ but varying a bit from one system to the next, corresponds to a linear $\mathrm{CH} \cdot \mathrm{O} / \mathrm{N} \mathrm{H}$-bonding arrangement. In order to establish the manner in which the spectroscopic parameters might be used to distinguish between a tetrel vs H-bond, $\theta$ was set to a series of values varying between $180^{\circ}$ and the precise angle that would present a linear $\mathrm{CH} \cdot \cdot \mathrm{O} / \mathrm{N}$ angle (approximately $110^{\circ}$ ) in $20^{\circ}$ increments. For each such angle, the remainder of the molecular geometry was fully optimized, including the $\mathrm{R}$ distance separating the two monomers.

Calculations were carried out within the context of Gaussian- $09^{69}$, with the MP2 treatment of electron correlation, in concert with an aug-cc-pVDZ basis set. This level of theory has demonstrated its accuracy for Hbonds as well as other noncovalent bonds of the sort examined here ${ }^{10,70-80}$. The presence of several methyl groups on the Lewis acid leads to strong coupling between the normal vibrational modes of the $\mathrm{CH}_{3}$ of interest and those of the others, which complicates any interpretation. In order to focus on the methyl vibrations of interest, and to decouple its modes from those of the others, the $\mathrm{H}$ atoms of the other methyl groups were replaced by D. Vibrational frequencies were calculated with the harmonic approximation. NMR chemical shielding was computed at the M06-2X/aug-cc-pVDZ level.

\section{RESULTS}

Each methyl group is subject to three stretching and three bending normal modes. Two of each are asymmetric and the third is symmetric. The symmetric bending mode is sometimes referred to as umbrella due to its resemblance of the opening and closing of an umbrella. The frequencies of all of these modes for the 
three Lewis acids considered here are reported in Table 1, along with their IR intensities. Note that the stretching modes lie in the general range of 3100 to $3200 \mathrm{~cm}^{-1}$, and that the asymmetric motions are associated with slightly higher frequencies than the symmetric mode. There is a somewhat larger gap between the symmetric and asymmetric bends of as much as $100 \mathrm{~cm}^{-1}$, which fall out in the $1320-1480 \mathrm{~cm}^{-1}$ range. All of the modes have large enough intensities that they ought to be observable, with the exception of the stretching bands of $\mathrm{NMe}_{4}{ }^{+}$. Also included in the bottom part of Table 1 are the calculated chemical shieldings of the $\mathrm{C}$ and $\mathrm{H}$ atoms of the methyl groups, all relative to the same atoms in tetramethylsilane (TMS). The negative values in Table 1 correspond to lesser shielding in these molecules than in TMS, i.e. downfield shifts.

The way in which each of these vibrational modes is influenced by the angle $\theta$ is illustrated in Fig 2 . The quantities graphed here are the changes in each frequency relative to the unperturbed Lewis acid monomer. Changes induced by tetrel bonding geometries $\left(\theta=180^{\circ}\right)$ are on the left, and H-bonding structures on the right. Solid curves refer to stretches and bending modes are indicated by broken curves. Red color is used to represent the symmetric modes, and asymmetric results are in blue.

Taking the $\mathrm{SMe}_{3}{ }^{+} \cdot \mathrm{NH}_{3}$ system as an example, the T-bonding geometry causes very small changes in the methyl stretching modes, all less than $10 \mathrm{~cm}^{-1}$, relative to the sulfonium. However, the bending frequencies are much more strongly affected, particularly the symmetric umbrella mode which shifts to lower frequency by 50 $\mathrm{cm}^{-1}$. As the $\mathrm{NH}_{3}$ nucleophile shifts around away from the $\mathrm{S}-\mathrm{C}$ axis and toward the $\mathrm{C}-\mathrm{H}$ proton, all of the bending vibrations shift to higher frequencies. The umbrella mode transitions from -50 to $+38 \mathrm{~cm}^{-1}$, a net change of 88 . The stretching frequencies move in the opposite direction, becoming smaller as the system transitions from $\mathrm{T}$ to H-bonding. This change is largely monotonic, although there is an upward bump over the last $20^{\circ}$ to fully linear $\mathrm{CH} \cdot \mathrm{N}$.

The overall net change, from tetrel to H-bonding configuration, is summarized in Table 2 where the diagnostic value of these vibrational frequencies is immediately apparent. The most dramatic changes between the two types of bonding scenarios are contained in the symmetric modes, which change by 67 and $78 \mathrm{~cm}^{-1}$ for stretching and bending, respectively, but the other modes also undergo substantial changes.

The first row of data in Table 2 reports the interaction energies of the two configurations. The H-bonded structure is more strongly bound than the TB However, the difference amounts to only $1.8 \mathrm{kcal} / \mathrm{mol}$, roughly $18 \%$. It is thus easy to imagine how the additional interactions with other groups within a protein or crystal could readily shift the configuration from one structure to the other, or to geometries intermediate between the two. The second row indicates how the displacement of the $\mathrm{NH}_{3}$ away from the $\mathrm{S}-\mathrm{C}$ axis and up toward the $\mathrm{C}$ $\mathrm{H}$ axis causes the expected increase in its distance from the methyl $\mathrm{C}$ atom.

The variation in NMR parameters is detailed in Fig 3. Again using $\mathrm{SMe}_{3}{ }^{+\cdot} \cdot \mathrm{NH}_{3}$ as our example, when the TB is formed, the ${ }^{13} \mathrm{C}$ atom is deshielded by $6 \mathrm{ppm}$ relative to the uncomplexed $\mathrm{SMe}_{3}{ }^{+}$monomer, with very 
little effect upon the methyl protons. As the $\mathrm{NH}_{3}$ moves away from the $\mathrm{S}-\mathrm{C}$ axis so as to engage in a $\mathrm{CH} \cdot \cdot \mathrm{N} \mathrm{HB}$ the shielding of the $\mathrm{C}$ atom increases quickly, rising by $5 \mathrm{ppm}$. At the same time, the $\mathrm{H}$ atom to which the $\mathrm{H}$ bond is being formed is deshielded by about $3 \mathrm{ppm}$. Since it is not always possible to elucidate the shift of a single proton in a methyl group by NMR methods, the green curve in Fig 3 shows the shielding of the entire methyl group as an average of all three protons. This quantity also drops, albeit not by as much as the single bridging proton. But its decrease of $0.7 \mathrm{ppm}$ should still be detectable. These parameters are displayed in the lower portion of Table 2, which reports all three methyl proton chemical shieldings.

When the $\mathrm{NH}_{3}$ nucleophile is replaced by $\mathrm{H}_{2} \mathrm{O}$, the patterns are generally similar but with some differences. All of the stretching frequencies drop in the transition from tetrel to H-bond, and the bending frequencies rise. These shifts are not quite monotonic. In particular, the bending frequencies experience a maximum for a geometry just short of the fully linear $\mathrm{HB}$, and there is a minimum in the asymmetric stretches at $\theta=140^{\circ}$, although the symmetric stretch does diminish smoothly. The $\mathrm{C}$ and $\mathrm{H}$ shielding patterns are rather similar for either nucleophile, with $\mathrm{C}$ rising and $\mathrm{H}$ dropping.

A glance at Table 2 reveals quantitative differences between the $\mathrm{NH}_{3}$ and $\mathrm{H}_{2} \mathrm{O}$ cases. For example, the symmetric stretch is smaller by $67 \mathrm{~cm}^{-1}$ for tetrel vs $\mathrm{H}$-bonding for the former, but only $25 \mathrm{~cm}^{-1}$ for the latter. This difference in magnitude persists for the umbrella bending motion, in that the $\mathrm{NH}_{3}$ blue shift of $78 \mathrm{~cm}^{-1}$ drops to only 33 for $\mathrm{H}_{2} \mathrm{O}$. One also sees a larger effect for $\mathrm{NH}_{3}$ when it comes to the bridging proton shielding change, $-3.4 \mathrm{ppm}$ as compared to $-1.7 \mathrm{ppm}$ for $\mathrm{H}_{2} \mathrm{O}$. The $\mathrm{C}$ shielding on the other hand, increases by roughly 5 ppm regardless of the base.

Replacement of the base by an anion leads to an ion pair for $\mathrm{SMe}_{3}{ }^{+} \cdot \mathrm{OCH}_{3}{ }^{-}$. Indeed, full optimization of this complex leads to the transition to a neutral pair by full transfer of either one of the methyl groups or a proton. Such a transfer occurs when the two ions move very close to one another so the loss of the desired ion pair character can be avoided if the intermolecular distance is held fixed. A R $(\mathrm{C} \cdot \mathrm{O})$ distance of $2.80 \AA$ was chosen for this purpose, which is consonant with the sorts of distances expected in biological systems. The ion pair character of this complex leads to a very high interaction energy, as much as $110 \mathrm{kcal} / \mathrm{mol}$.

Despite the change in character of the nucleophile to a fully charged anion, the behaviors of the various spectroscopic parameters are changed very little. Stretching frequencies diminish as the system transitions from $\mathrm{T}$ to H-bond, particularly the symmetric stretch, and the bending frequencies all increase. Also quite similar are the behaviors of the $\mathrm{C}$ and $\mathrm{H}$ chemical shieldings in Fig 3.

Where the change of nucleophile character exercises its primary influence is with respect to the magnitudes of these changes. Considering the symmetric stretch for example, the change from $\mathrm{T}$ to H-bond lowers this frequency by less than $80 \mathrm{~cm}^{-1}$ for the neutral bases, but by $300 \mathrm{~cm}^{-1}$ for $\mathrm{OMe}^{-}$. Although not as dramatic, the asymmetric stretching modes also drop by more for the anion than for the neutrals. Bending frequencies are all 
higher for the HB than for the TB, and again this difference is larger in magnitude for the anion. These same amplifications extend to the NMR parameters as well. The $\mathrm{C}$ shielding rises by $25.7 \mathrm{ppm}$ for the anion, and that of the shared proton drops by $7.5 \mathrm{ppm}$. Both of these differences are considerably larger than those of the neutral bases.

The $\mathrm{SMe}_{2} \cdot \mathrm{OH}^{-}$system removes the positive charge from the Lewis acid, leaving a neutral-anion interaction. The behavior of the spectroscopic parameters nonetheless fairly closely mimic the cation-anion $\mathrm{SMe}_{3}{ }^{+\cdot \cdot} \mathrm{OCH}_{3}{ }^{-}$ complex, at least qualitatively. The transition from $\mathrm{T}$ to $\mathrm{H}$-bonded structure raises the $\mathrm{CH}$ bending frequencies and reduces the stretching modes. But what is most notable are the magnitudes. The umbrella motion of the methyl group undergoes a $65 \mathrm{~cm}^{-1}$ blue shift, by far the largest of any system examined here. Perhaps even more striking is the enormous red shifts of the $\mathrm{CH}$ stretches, capping off at nearly $1000 \mathrm{~cm}^{-1}$ for the symmetric motion. However, it should be underscored that this particular mode changes its character as the nucleophile moves away from the S-C axis and toward C-H. While the internal motion is clearly that of a symmetric stretch in the $\mathrm{TB}$, it changes into a stretch of the single $\mathrm{CH}$ that is pointing directly toward the $\mathrm{OH}^{-}$. The same is true of some of the other systems, but to a lesser extent. The NMR behavior of the neutral-anion $\mathrm{SMe}_{2} \cdot \mathrm{OH}^{-}$adduct is consistent with the IR pattern in that the bridging proton undergoes a very large downfield shift. Although this shift is only $1.4 \mathrm{ppm}$ in the TB, it rises to a full $12.8 \mathrm{ppm}$ in the HB geometry, a change of more than $11 \mathrm{ppm}$. Unlike all of the other systems, the $\mathrm{C}$ shielding is smaller in the HB than the TB, albeit by only 2 ppm, but still ought to be detectable.

Some of the anomalies of the $\mathrm{SMe}_{2} \cdot \mathrm{OH}^{-}$system are attenuated for the larger $\mathrm{HCOO}^{-}$anion. Again one sees a rise in the bending frequencies and an opposite trend for the stretches, but the change from tetrel to H-bonded structures is considerably smaller. The changes in the bending vibration frequencies, for example, are all cut in half. And in particular, the drop in the symmetric stretch is much smaller, dropping from 1035 to $128 \mathrm{~cm}^{-1}$. The switch from $\mathrm{OH}^{-}$to the larger $\mathrm{HCOO}^{-}$also brings back the usual pattern of a larger $\mathrm{C}$ shielding in the $\mathrm{HB}$ than in the TB.

With regard to Lewis acid, one can switch gears and change from a sulfonium cation to one wherein the methyl is attached to a $\mathrm{N}$ atom. The $\mathrm{NMe}_{4}{ }^{+}$cation was paired with the peptide bond mimic $\mathrm{HCONH}_{2}$ so as to ascertain the generality of the trends. These patterns are relatively unchanged: the bending modes occur at a higher frequency in the HB than TB while the stretching frequencies are red-shifted. In quantitative terms, the symmetric stretch is reduced by $19 \mathrm{~cm}^{-1}$ in $\mathrm{NMe}_{4}^{+} \cdot \cdot \mathrm{OCHNH}_{2}$, and the umbrella bend rises by $46 \mathrm{~cm}^{-1}$. Also in common with S-containing Lewis acids, the NMR shielding of $\mathrm{C}$ is higher in the $\mathrm{HB}$, while that of the bridging proton is lower. The actual amounts are generally comparable to the complexes involving a sulfonium with a neutral base. 
Another aspect of the vibrational spectra that can useful for diagnostic purposes is the set of intensities. The intensities computed for both the tetrel and $\mathrm{CH} \cdot \mathrm{X} \mathrm{H}$-bonded geometries are displayed in Table 3 . In general, there is not a profound difference between the intensities of the tetrel and H-bonded structures, but there are a few exceptions to this rule that might be of practical importance. The symmetric stretching mode in the third row of Table 3 provides the most obvious example. There is a dramatic enhancement upon going from TB to $\mathrm{HB}$, in some cases by several orders of magnitude. The asymmetric stretches follow this pattern as well, but not as consistently, and to a lesser degree. It might be borne in mind that the symmetric stretching motion evolves in the H-bonded geometry into more of the stretch of a single $\mathrm{C}-\mathrm{H}$ bond, that of the proton involved in the $\mathrm{H}$ bond bridge. This evolution is most obvious in the case of the $\mathrm{SMe}_{3}{ }^{+} \cdot \cdot \mathrm{OCH}_{3}{ }^{-}$and $\mathrm{SMe}_{2} \cdot \mathrm{OH}^{-}$systems.

\section{Dependence upon Intermolecular Separation}

It might be noted that the data discussed heretofore reflect geometric optimization that allows the nucleophile to freely approach the Lewis acid with no restrictions on proximity. Some of these distances of approach are quite short, less than $3 \AA$. Again, the numerous restraints that would be imposed on the pair by the rest of the protein structure would normally not allow such an unfettered and free approach. Nonetheless, the trends observed in the data here would likely be preserved even if the two subunits are held further apart, albeit the numerical values would be reduced.

Taking the $\mathrm{SMe}_{3}{ }^{+} \cdot \mathrm{NH}_{3}$ prototype system as an example, Table 4 illustrates the behavior of the various spectroscopic and energetic parameters as the two subunits are pulled apart. Considering first the stretching frequencies, in the TB configuration all of their shifts relative to the isolated monomer are small, less than 10 $\mathrm{cm}^{-1}$, and remain so as the two subunits are pulled apart. These shifts are much larger for the $\mathrm{CH}^{\cdot} \cdot \mathrm{N}$ H-bonded structures, and there is a slow tapering off as the intermolecular distance increases. The red shift of the symmetric stretch, for example, drops smoothly from $63 \mathrm{~cm}^{-1}$ for $\mathrm{R}=3.29 \AA$, down to $37 \mathrm{~cm}^{-1}$ when $\mathrm{R}$ is elongated to $4.1 \AA$. With respect to the bending frequencies, they are red-shifted for the TB, and shift to the blue for HB. In every case, the amount of this shift diminishes smoothly as the two groups are pulled apart. Taking the umbrella motion as an example, the red shift for the TYB drops from 50 to $18 \mathrm{~cm}^{-1}$, while the blue shift of the HB conformation diminishes from 28 to $16 \mathrm{~cm}^{-1}$.

Turning next to the NMR shielding in the lower section of Table 4, the patterns witnessed for the equilibrium separations are retained as the intermolecular distance is elongated. The shift of the $\mathrm{C}$ nucleus in the TB structure remains in the downfield direction, even if the magnitude of this shift is diminished. Likewise, the downfield shift of the bridging proton, the distinguishing feature for the HB configuration, remains intact. These two quantities are both larger than 1 ppm, even for the long intermolecular separation of $4.1 \AA$. It is underscored that NMR patterns, like the IR shifts, are all large enough in magnitude, so as to enable one to distinguish the TB from the HB structures via spectroscopic measurements. It may be noted finally from the 
first row of Table 4 that the interaction energy decreases fairly slowly upon separation. Even for $R(C \cdot \cdot N)$ as long as $4.1 \AA$, the interaction energies for both types of interaction retain roughly $70 \%$ of their optimized values.

\section{DISCUSSION}

As mentioned earlier, one might be tempted to classify the tetrel-bonding position, viz. wherein $\theta \sim 180^{\circ}$, as a trifurcated HB. While this may be correct in a formal geometric sense, it does not accurately reflect the actual source of the bonding. Using NBO inter-orbital charge shifts as the traditional barometer of the sort of bonding that is present, these interactions are true tetrel bonds. The perturbation energy $\mathrm{E}(2)$ that corresponds to the charge transfer from the nucleophile lone pair to the $\sigma^{*}(\mathrm{~S}-\mathrm{C})$ ( or $\sigma^{*}(\mathrm{~N}-\mathrm{C})$ ) antibonding orbital is substantial and there is no such transfer to the $\sigma^{*}(\mathrm{C}-\mathrm{H})$ antibonds that would be characteristic of a HB. Specifically, E(2) for the former varies from 1.67 to $5.33 \mathrm{kcal} / \mathrm{mol}$, depending upon the system, while there is no such transfer into the $\mathrm{CH}$ antibonding orbitals. Of course, the aforementioned deals specifically with an idealized position of the nucleophile, directly along the S-C bond axis. On the opposite extreme, the nucleophile may lie directly along a $\mathrm{C}-\mathrm{H}$ axis, in which case NBO treatment reveals the replacement of the TB with a classic $\mathrm{CH} \cdot \mathrm{X} H \mathrm{HB}$.

The situation in many proteins is unlikely to be so clear cut, and the nucleophile will typically lie in a position intermediate between these two extremes. Indeed, NBO analysis of the wave functions show how the transition of the nucleophile between these two positions weakens the TB as the HBgains strength, so that these intermediate geometries can be described as a mix of these two sorts of noncovalent bonds. Fig 4 illustrates this behavior for the prototype $\mathrm{SMe}_{3}{ }^{+\cdot} \cdot \mathrm{NH}_{3}$ system. Whether TB or $\mathrm{HB}$, the bulk of the charge emanates from the $\mathrm{N}$ lone pair. In the case of a TB, the charge transfers to the $\sigma^{*}(\mathrm{CS})$ antibonding orbital, whereas a HB is marked by transfer into the corresponding $\sigma^{*}(\mathrm{CH})$ orbital. The blue line in Fig 4 shows how the $\mathrm{E}(2)$ for the former transfer gradually diminishes as the nucleophile is moved from tetrel into H-bonding position, while the $\mathrm{H}$ bonding correlate grows (red curve). Together, these two plots portray a continuous change from one sort of bond to the other, while intermediate geometries contain elements of both. The data illustrated in Figs 2 and 3 provide a framework for interpreting the spectroscopic information along this continuum and permit an estimate to be made as to the relative proportions of the two sorts of noncovalent bonds to the total interaction.

Again with respect to the angular position of a nucleophile, the energy of the system is fairly insensitive to the precise positioning. As is evident in Table 2, in most systems there is a slight preference for the H-bonding geometry so the nucleophile might tend toward this position in the complete absence of any other factors. However, there are a host of internal geometric constraints within the confines of a protein that are related to contacts between the various other residues. It is unlikely therefore that the structures of the interacting pairs will be heavily influenced to adopt the HB over the TB conformation, or vice versa, by these weak intrinsic 
geometric preferences. And indeed, the tetrel-bonding geometry is a common one, in for example a series of methyltransferase enzymes, despite an intrinsic preference for a $\mathrm{CH}^{*} \mathrm{O}$ alignment.

The full potential energy surfaces of the actual systems in Fig 1 contain multiple minima. In addition to minima that might arise for a TB or HB complex, there are also minima associated with geometries that are less relevant to the noncovalent bonds of interest here, and that would be precluded within the confines of certain proteins. In the $\mathrm{SMe}_{3}{ }^{+} \cdot \mathrm{NH}_{3}$ system, for example, the global minimum places the $\mathrm{NH}_{3}$ opposite the $\mathrm{S}$ atom in what might be called a chalcogen bond, combined with a pair of highly distorted $\mathrm{CH} \cdot \cdot \mathrm{N}$ HBs. The global minimum for $\mathrm{SMe}_{3}{ }^{+} \cdot \mathrm{OH}_{2}$ contains a set of three bent $\mathrm{CH} \cdot \cdot \mathrm{O} \mathrm{HBs}$, each arising from a different methyl group..

An earlier set of calculations ${ }^{81}$ had directly compared the energetics and spectral features of SC $\cdot \mathrm{O}$ TBs with their $\mathrm{CH}^{\cdots} \mathrm{O}$ HB analogues. Sulfur-containing Lewis acids like $\mathrm{SMe}_{3}{ }^{+}$and its neutral $\mathrm{SMe}_{2}$-type counterpart were paired with the $\mathrm{O}$ electron donor atom of $\mathrm{N}$-methylacetamide. Although the full spectrum of geometries intermediate between these two extremes was not considered, nor were IR spectra evaluated, the results are consistent with those described above. As noted here, the $\mathrm{CH} \cdot \cdot \mathrm{O}$ HBs have a slight energetic edge over the TBs. ${ }^{1} \mathrm{H}$ NMR chemical shieldings were considerably smaller for the HBs than for the TBs, consistent with the data computed here for a wide range of systems.

There is another study in the literature with which certain of our data can be compared, even if only trends involving somewhat different systems, and for only one particular parameter. Southern and Bryce ${ }^{44}$ had computed ${ }^{13} \mathrm{C}$ NMR chemical shifts for a variety of tetrel-bonded dimers. They found in all cases that the shielding on the tetrel-bonding $\mathrm{C}$ atom was reduced in comparison to TMS, as was noted here for other Lewis acids. This deshielding diminishes as the two groups are pulled apart, consistent with the trend in Table 4 . Their extraction of both experimental and theoretical ${ }^{13} \mathrm{C}$ chemical shifts from tetrel bonded systems in the Cambridge Structural Database confirmed the deshielding of this atom, as found in the calculations described above. The magnitudes of these experimental shifts are in the 3-10 ppm range, quantitatively consonant with our own calculated data. And finally, a recent work ${ }^{82}$ has demonstrated that quantum calculations can reliably reproduce trends in ${ }^{13} \mathrm{C}$ NMR chemical shifts in the related halogen bonds.

\section{CONCLUSIONS}

The systems examined here are rather diverse. They include a positively charged sulfonium interacting with a neutral $\mathrm{N}$ or $\mathrm{O}$ atom, as well as a methoxide anion. A neutral thioether was allowed to pair with a small $\mathrm{OH}^{-}$ anion as well at the larger $\mathrm{COO}^{-}$carboxylate. The methyl-donating atom of the Lewis acid was also changed from $\mathrm{S}$ to $\mathrm{N}$ in the case of the $\mathrm{NMe}_{4}^{+}$cation, paired with the amide O. Despite the diversity of systems examined, there were several trends that appear universal. As the tetrel-bonded geometry with a linear $\mathrm{R}-\mathrm{C} \cdot{ }^{\cdot} \mathrm{O}$ configuration transitions to a $\mathrm{CH}^{\cdot} \cdot \mathrm{O}$ H-bonded geometry, the methyl $\mathrm{C}-\mathrm{H}$ stretching frequencies shift to the red, most notably the symmetric stretching motion. The bending frequencies move in the opposite direction, with 
the symmetric umbrella mode showing the largest variation. The same transition toward a H-bond structure produces a large downfield shift in the bridging H NMR signal, sizable enough that even the average of all three methyl $\mathrm{H}$ shifts ought to be measurable. The ${ }^{13} \mathrm{C}$ shielding increases on going from tetrel to $\mathrm{H}$-bonded geometry, with the single exception of the $\mathrm{SMe}_{2} \cdot \mathrm{OH}^{-}$complex where a rather small deshielding occurs. Of course, the magnitudes of these changes are highly dependent upon the particular system. For example, the ${ }^{13} \mathrm{C}$ shielding difference between the two configurations varies from less than $2 \mathrm{ppm}$ to as much as $26 \mathrm{ppm}$ for the $\mathrm{SMe}_{3}{ }^{+} \cdot \mathrm{OCH}_{3}{ }^{-}$ion pair. Likewise for the IR frequency changes, where the umbrella bending mode change, for example, varies from a minimum of $33 \mathrm{~cm}^{-1}$ for $\mathrm{SMe}_{3}{ }^{+} \cdot \mathrm{OH}_{2}$ up to as much as $128 \mathrm{~cm}^{-1}$ for $\mathrm{SMe}_{2} \cdot \mathrm{OH}^{-}$. $\mathrm{But}$ the consistency of the direction of change, coupled with its large magnitude, ought to provide a framework for interpretation of measured spectra as to the nature of the noncovalent bonding that is present. 


\section{REFERENCES}

1. Hassel, O. Structural Aspects of Interatomic Charge-Transfer Bonding. Science 1970, 170, 497-502.

2. Rosenfield, R. E.; Parthasarathy, R.; Dunitz, J. D. Directional Preferences of Nonbonded Atomic Contacts with Divalent Sulfur. 1. Electrophiles and Nucleophiles. J. Am. Chem. Soc. 1977, 99, 4860-4862.

3. Burling, F. T.; Goldstein, B. M. Computational Studies of Nonbonded Sulfur-Oxygen and SeleniumOxygen Interactions in the Thiazole and Selenazole Nucleosides. J. Am. Chem. Soc. 1992, 114, 2313-2320.

4. Iwaoka, M.; Tomoda, S. Nature of the Intramolecular Se $\cdots$ N Nonbonded Interaction of 2Selenobenzylamine Derivatives. An Experimental Evaluation by ${ }^{1} \mathrm{H},{ }^{77} \mathrm{Se}$, and ${ }^{15} \mathrm{~N}$ NMR Spectroscopy. $J$. Am. Chem. Soc. 1996, 118, 8077-8084.

5. Lommerse, J. P. M.; Stone, A. J.; Taylor, R.; Allen, F. H. The Nature and Geometry of Intermolecular Interactions between Halogens and Oxygen or Nitrogen. J. Am. Chem. Soc. 1996, 118, 3108-3116.

6. Alkorta, I.; Rozas, S.; Elguero, J. Charge-Transfer Complexes between Dihalogen Compounds and Electron Donors. J. Phys. Chem. A 1998, 102, 9278-9285.

7. Zierkiewicz, W.; Bieńko, D. C.; Michalska, D.; Zeegers-Huyskens, T. Theoretical Investigation of the Halogen Bonded Complexes between Carbonyl Bases and Molecular Chlorine. J. Comput. Chem. 2015, 36, 821-832.

8. Fanfrlík, J.; Zierkiewicz, W.; Švec, P.; Růžičková, Z.; Řezáč, J.; Michalczyk, M.; Růžička, A.; Michalska, D.; Hobza, P. Pnictogen Bonding in Pyrazine $• \mathrm{PnX} 5(\mathrm{Pn}=\mathrm{P}, \mathrm{As}, \mathrm{Sb}$ and $\mathrm{X}=\mathrm{F}, \mathrm{Cl}, \mathrm{Br})$ Complexes. J. Mol. Model. 2017, 23, 328.

9. Politzer, P.; Murray, J. S.; Clark, T. $\Sigma$-Hole Bonding: A Physical Interpretation. Top. Curr. Chem. 2015, $358,19-42$.

10. Kerdawy, A. E.; Murray, J. S.; Politzer, P.; Bleiziffer, P.; Heßelmann, A.; Görling, A.; Clark, T. Directional Noncovalent Interactions: Repulsion and Dispersion. J. Chem. Theory Comput. 2013, 9, 22642275.

11. Scheiner, S. Detailed Comparison of the Pnicogen Bond with Chalcogen, Halogen and Hydrogen Bonds. Int. J. Quantum Chem. 2013, 113, 1609-1620.

12. Guo, X.; An, X.; Li, Q. Se $\cdots \mathrm{N}$ Chalcogen Bond and Se $\cdots X$ Halogen Bond Involving $\mathrm{F}_{2} \mathrm{C}=$ Se: Influence of Hybridization, Substitution, and Cooperativity. J. Phys. Chem. A 2015, 119, 3518-3527.

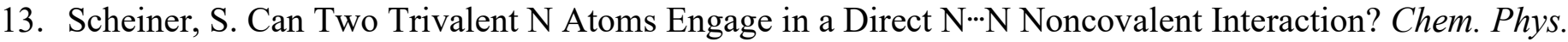
Lett. 2011, 514, 32-35.

14. Zhuo, H.; Li, Q.; Li, W.; Cheng, J. The Dual Role of Pnicogen as Lewis Acid and Base and the Unexpected Interplay between the Pnicogen Bond and Coordination Interaction in $\mathrm{H}_{3} \mathrm{~N} \cdots \mathrm{FH}_{2} \mathrm{X} \cdots \mathrm{MCN}(\mathrm{X}=\mathrm{P}$ and $\mathrm{As} ; \mathrm{M}$ $=\mathrm{Cu}, \mathrm{Ag}$, and $\mathrm{Au}) . \mathrm{New}$ J. Chem. 2015, 39, $2067-2074$.

15. Esrafili, M. D.; Asadollahi, S.; Dadban Shahamat, Y. Competition between Chalcogen Bond and Halogen Bond Interactions in $\mathrm{YOX}_{4}: \mathrm{NH}_{3}(\mathrm{Y}=\mathrm{S}, \mathrm{Se} ; \mathrm{X}=\mathrm{f}, \mathrm{Cl}, \mathrm{Br})$ Complexes: An Ab Initio Investigation. Struct. Chem. 2016, 27, 1439-1447.

16. Scheiner, S. Effects of Multiple Substitution Upon the P..N Noncovalent Interaction. Chem. Phys. 2011, 387, 79-84.

17. Bauzá, A.; Mooibroek, T. J.; Frontera, A. Tetrel-Bonding Interaction: Rediscovered Supramolecular Force? Angew. Chem. Int. Ed. 2013, 52, 12317-12321.

18. Rossi, A. R.; Jasinski, J. M. Theoretical Studies of Neutral Silane-Ammonia Adducts. Chem. Phys. Lett. 1990, 169, 399-404.

19. Alkorta, I.; Rozas, I.; Elguero, J. Molecular Complexes between Silicon Derivatives and Electron-Rich Groups. J. Phys. Chem. A 2001, 105, 743-749.

20. Vojinović, K.; McLachlan, L. J.; Hinchley, S. L.; Rankin, D. W. H.; Mitzel, N. W. Strong Intramolecular

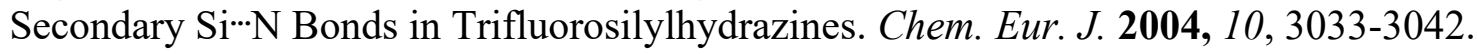

21. Hagemann, M.; Berger, R. J. F.; Hayes, S. A.; Stammler, H.-G.; Mitzel, N. W. N,N-

Dimethylaminopropylsilane: A Case Study on the Nature of Weak Intramolecular Si $\cdots N$ Interactions. Chem. Eur. J. 2008, 14, 11027-11038. 
22. Matczak, P. Theoretical Investigation of the $\mathrm{N} \rightarrow$ Sn Coordination in $\left(\mathrm{Me}_{3} \mathrm{SnCN}\right)_{2}$. Struct. Chem. 2015, 26, 301-318.

23. Mahmoudi, G.; Bauza, A.; Frontera, A.; Garczarek, P.; Stilinovic, V.; Kirillov, A. M.; Kennedy, A.; RuizPerez, C. Metal-Organic and Supramolecular Lead(Ii) Networks Assembled from Isomeric

Nicotinoylhydrazone Blocks: The Effects of Ligand Geometry and Counter-Ion on Topology and Supramolecular Assembly. CrystEngComm 2016, 18, 5375-5385.

24. Marín-Luna, M.; Alkorta, I.; Elguero, J. A Theoretical Study of the $\mathrm{H}_{n} \mathrm{~F}_{4-n} \mathrm{Si}$ :N-Base $(\mathrm{n}=1-4)$ TetrelBonded Complexes. Theor. Chem. Acc. 2017, 136, 41-48.

25. Grabowski, S. J.; Sokalski, W. A. Are Various $\Sigma$-Hole Bonds Steered by the Same Mechanisms? ChemPhysChem. 2017, 18, 1569-1577.

26. Zierkiewicz, W.; Michalczyk, M.; Scheiner, S. Implications of Monomer Deformation for Tetrel and Pnicogen Bonds. Phys. Chem. Chem. Phys. 2018, 20, 8832-8841.

27. Donald, K. J.; Tawfik, M. The Weak Helps the Strong: Sigma-Holes and the Stability of $\mathrm{MF}_{4} \cdot \mathrm{Base}$ Complexes. J. Phys. Chem. A 2013, 117, 14176-14183.

28. Scheiner, S. Systematic Elucidation of Factors That Influence the Strength of Tetrel Bonds. J. Phys. Chem. A 2017, 121, 5561-5568.

29. García-Llinás, X.; Bauzá, A.; Seth, S. K.; Frontera, A. Importance of R-CF $\mathrm{CF}_{3} \mathrm{O}$ Tetrel Bonding Interactions in Biological Systems. J. Phys. Chem. A 2017, 121, 5371-5376.

30. Azofra, L. M.; Scheiner, S. Tetrel, Chalcogen, and $\mathrm{CH} \cdot \mathrm{O}$ Hydrogen Bonds in Complexes Pairing Carbonyl-Containing Molecules with 1, 2, and 3 Molecules of $\mathrm{CO}_{2}$. J. Chem. Phys. 2015, 142, 034307.

31. Nziko, V. d. P. N.; Scheiner, S. Comparison of $\pi$-Hole Tetrel Bonding with $\sigma$-Hole Halogen Bonds in Complexes of XCN (X=F, Cl, Br, I) and $\mathrm{NH}_{3}$. Phys. Chem. Chem. Phys. 2016, 18, 3581-3590.

32. Liu, M.; Li, Q.; Scheiner, S. Comparison of Tetrel Bonds in Neutral and Protonated Complexes of pyridine $\mathrm{TF}_{3}$ and furan $\mathrm{TF}_{3}(\mathrm{~T}=\mathrm{C}, \mathrm{Si}$, and $\mathrm{Ge})$ with $\mathrm{NH}_{3}$. Phys. Chem. Chem. Phys. 2017, 19, 5550-5559.

33. Wei, Y.; Li, Q.; Scheiner, S. The П-Tetrel Bond and Its Influence on Hydrogen Bonding and Proton Transfer. ChemPhysChem. 2018, 19, 736-743.

34. Zierkiewicz, W.; Michalczyk, M.; Scheiner, S. Comparison between Tetrel Bonded Complexes Stabilized by $\Sigma$ and $\Pi$ Hole Interactions. Molecules 2018, 23, 1416.

35. Dong, W.; Li, Q.; Scheiner, S. Comparative Strengths of Tetrel, Pnicogen, Chalcogen, and Halogen Bonds and Contributing Factors. Molecules 2018, 23, 1681.

36. Scheiner, S. Steric Crowding in Tetrel Bonds. J. Phys. Chem. A 2018, 122, 2550-2562.

37. Scheiner, S. Highly Selective Halide Receptors Based on Chalcogen, Pnicogen, and Tetrel Bonds. Chem. Eur. J. 2016, 22, 18850-18858.

38. Scheiner, S. Assembly of Effective Halide Receptors from Components. Comparing Hydrogen, Halogen, and Tetrel Bonds. J. Phys. Chem. A 2017, 121, 3606-3615.

39. Scheiner, S. Comparison of Halide Receptors Based on H, Halogen, Chalcogen, Pnicogen, and Tetrel Bonds. Faraday Disc. 2017, 203, 213-226.

40. Scheiner, S. Tetrel Bonding as a Vehicle for Strong and Selective Anion Binding. Molecules 2018, 23, 1147-1155.

41. Thomas, S. P.; Pavan, M. S.; Guru Row, T. N. Experimental Evidence for 'Carbon Bonding' in the Solid State from Charge Density Analysis. Chem. Commun. 2014, 50, 49-51.

42. Bauzá, A.; Mooibroek, T. J.; Frontera, A. Tetrel Bonding Interactions. The Chemical Record 2016, 16, 473-487.

43. Bauzá, A.; Frontera, A. $\mathrm{RCH}_{3} \cdots \mathrm{O}$ Interactions in Biological Systems: Are They Trifurcated H-Bonds or Noncovalent Carbon Bonds? Cryst. 2016, 6, 26.

44. Southern, S. A.; Bryce, D. L. NMR Investigations of Noncovalent Carbon Tetrel Bonds. Computational Assessment and Initial Experimental Observation. J. Phys. Chem. A 2015, 119, 11891-11899.

45. Horowitz, S.; Dirk, L. M. A.; Yesselman, J. D.; Nimtz, J. S.; Adhikari, U.; Mehl, R. A.; Scheiner, S.; Houtz, R. L.; Al-Hashimi, H. M.; Trievel, R. C. Conservation and Functional Importance of Carbon- 
Oxygen Hydrogen Bonding in Adomet-Dependent Methyltransferases. J. Am. Chem. Soc. 2013, 135, 15536-15548.

46. Poulin, M. B.; Schneck, J. L.; Matico, R. E.; McDevitt, P. J.; Huddleston, M. J.; Hou, W.; Johnson, N. W.; Thrall, S. H.; Meek, T. D.; Schramm, V. L. Transition State for the NSD2-Catalyzed Methylation of Histone H3 Lysine 36. Proc. Nat. Acad. Sci., USA 2016, 113, 1197-1201.

47. Zhang, J.; Klinman, J. P. Convergent Mechanistic Features between the Structurally Diverse N- and OMethyltransferases: Glycine N-Methyltransferase and Catechol O-Methyltransferase. J. Am. Chem. Soc. 2016, 138, 9158-9165.

48. Linscott, J. A.; Kapilashrami, K.; Wang, Z.; Senevirathne, C.; Bothwell, I. R.; Blum, G.; Luo, M. Kinetic Isotope Effects Reveal Early Transition State of Protein Lysine Methyltransferase Set8. Proc. Nat. Acad. Sci., USA 2016, 113, E8369-E8378.

49. Świderek, K.; Tuñón, I.; Williams, I. H.; Moliner, V. Insights on the Origin of Catalysis on Glycine NMethyltransferase from Computational Modeling. J. Am. Chem. Soc. 2018, 140, 4327-4334.

50. Mani, D.; Arunan, E. The $\mathrm{X}-\mathrm{CY}(\mathrm{X}=\mathrm{O} / \mathrm{F}, \mathrm{Y}=\mathrm{O} / \mathrm{S} / \mathrm{F} / \mathrm{Cl} / \mathrm{Br} / \mathrm{N} / \mathrm{P})$ 'Carbon Bond' and Hydrophobic Interactions. Phys. Chem. Chem. Phys. 2013, 15, 14377-14383.

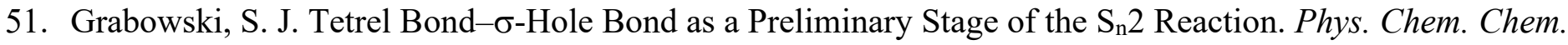
Phys. 2014, 16, 1824-1834.

52. Mani, D.; Arunan, E. The $\mathrm{X}-\mathrm{C} \cdots \pi(\mathrm{X}=\mathrm{F}, \mathrm{Cl}, \mathrm{Br}, \mathrm{CN})$ Carbon Bond. J. Phys. Chem. A 2014, 118, $10081-$ 10089.

53. Li, Q.-Z.; Zhuo, H.-Y.; Li, H.-B.; Liu, Z.-B.; Li, W.-Z.; Cheng, J.-B. Tetrel-Hydride Interaction between $\mathrm{XH}_{3} \mathrm{~F}(\mathrm{X}=\mathrm{C}, \mathrm{Si}, \mathrm{Ge}, \mathrm{Sn})$ and $\mathrm{HM}(\mathrm{M}=\mathrm{Li}, \mathrm{Na}, \mathrm{BeH}, \mathrm{MgH})$. J. Phys. Chem. A 2015, 119, 2217-2224.

54. Esrafili, M. D.; Kiani, H.; Mohammadian-Sabet, F. Tuning of Carbon Bonds by Substituent Effects: An Ab Initio Study. Mol. Phys. 2016, 114, 3658-3668.

55. Del Bene, J. E.; Alkorta, I.; Elguero, J. Anionic Complexes of $\mathrm{F}^{-}$and $\mathrm{Cl}^{-}$with Substituted Methanes: Hydrogen, Halogen, and Tetrel Bonds. Chem. Phys. Lett. 2016, 655-656, 115-119.

56. Liu, M.; Li, Q.; Cheng, J.; Li, W.; Li, H.-B. Tetrel Bond of Pseudohalide Anions with $\mathrm{XH}_{3} \mathrm{~F}(\mathrm{X}=\mathrm{C}, \mathrm{Si}$, Ge, and Sn) and Its Role in $\mathrm{S}_{\mathrm{n}} 2$ Reaction. J. Chem. Phys. 2016, 145, 224310.

57. Marín-Luna, M.; Alkorta, I.; Elguero, J. Cooperativity in Tetrel Bonds. J. Phys. Chem. A 2016, 120, 648656.

58. Esrafili, M. D.; Nurazar, R.; Mohammadian-Sabet, F. Cooperative Effects between Tetrel Bond and Other $\Sigma$-Hole Bond Interactions: A Comparative Investigation. Mol. Phys. 2015, 113, 3703-3711.

59. Gu, Y.; Kar, T.; Scheiner, S. Comparison of the $\mathrm{CH} \cdots \mathrm{N}$ and $\mathrm{CH} \cdots \mathrm{O}$ Interactions Involving Substituted Alkanes. J. Mol. Struct. 2000, 552, 17-31.

60. Scheiner, S.; Kar, T. Spectroscopic and Structural Signature of the CH--O H-Bond. J. Phys. Chem. A 2008, 112, 11854-11860.

61. Scheiner, S. Identification of Spectroscopic Patterns of CH--O H-Bonds in Dipeptides. J. Phys. Chem. B 2009, 113, 10421-10427.

62. Fick, R. J.; Clay, M. C.; Vander Lee, L.; Scheiner, S.; Al-Hashimi, H.; Trievel, R. C. Water-Mediated Carbon-Oxygen Hydrogen Bonding Facilitates S-Adenosylmethionine Recognition in the Reactivation Domain of Cobalamin-Dependent Methionine Synthase. Biochem. 2018, 57, 3733-3740.

63. Ludwig, M. L.; Matthews, R. G. Structure-Based Perspectives on B12-Dependent Enzymes. Ann. Rev. Biochem. 1997, 66, 269-313.

64. Schubert, H. L.; Blumenthal, R. M.; Cheng, X. Many Paths to Methyltransfer: A Chronicle of Convergence. Trends Biochem. Sci. 2003, 28, 329-335.

65. Byer, A. S.; Yang, H.; McDaniel, E. C.; Kathiresan, V.; Impano, S.; Pagnier, A.; Watts, H.; Denler, C.; Vagstad, A. L.; Piel, J., et al. Paradigm Shift for Radical S-Adenosyl-L-Methionine Reactions: The Organometallic Intermediate $\Omega$ Is Central to Catalysis. J. Am. Chem. Soc. 2018, 140, 8634-8638.

66. Zhang, X.; Bruice, T. C. Enzymatic Mechanism and Product Specificity of Set-Domain Protein Lysine Methyltransferases. Proc. Nat. Acad. Sci., USA 2008, 105, 5728-5732. 
67. Cybulski, S. M.; Scheiner, S. Hydrogen Bonding and Proton Transfers Involving the Carboxylate Group. J. Am. Chem. Soc. 1989, 111, 23-31.

68. Thorsen, Thor S.; Matt, R.; Weis, William I.; Kobilka, Brian K. Modified T4 Lysozyme Fusion Proteins Facilitate G Protein-Coupled Receptor Crystallogenesis. Structure 2014, 22, 1657-1664.

69. Frisch, M. J.; Trucks, G. W.; Schlegel, H. B.; Scuseria, G. E.; Robb, M. A.; Cheeseman, J. R.; Scalmani, G.; Barone, V.; Mennucci, B.; Petersson, G. A., et al. Gaussian 09, Revision B.01; Wallingford, CT, 2009.

70. Spada, L.; Gou, Q.; Geboes, Y.; Herrebout, W. A.; Melandri, S.; Caminati, W. Rotational Study of Dimethyl Ether-Chlorotrifluoroethylene: Lone Pair $\cdots \Pi$ Interaction Links the Two Subunits. J. Phys. Chem. A 2016, 120, 4939-4943.

71. Shukla, R.; Chopra, D. "Pnicogen Bonds" or "Chalcogen Bonds": Exploiting the Effect of Substitution on the Formation of P...Se Noncovalent Bonds. Phys. Chem. Chem. Phys. 2016, 18, 13820-13829.

72. Tang, Q.; Li, Q. Non-Additivity of F Substituent in Enhancing the Halogen Bond in $\mathrm{C}_{6} \mathrm{H}_{5} \mathrm{I} \cdots \mathrm{NCH}$. Comput. Theor. Chem. 2015, 1070, 21-26.

73. Geboes, Y.; Proft, F. D.; Herrebout, W. A. Expanding Lone Pair $\cdots \Pi$ Interactions to Nonaromatic Systems and Nitrogen Bases: Complexes of $\mathrm{C}_{2} \mathrm{~F}_{3} \mathrm{X}(\mathrm{X}=\mathrm{F}, \mathrm{Cl}, \mathrm{Br}, \mathrm{I})$ and TMA-D9. J. Phys. Chem. A 2015, 119, 5597-5606.

74. Sanchez-Sanz, G.; Trujillo, C.; Alkorta, I.; Elguero, J. Intramolecular Pnicogen Interactions in Phosphorus and Arsenic Analogues of Proton Sponges. Phys. Chem. Chem. Phys. 2014, 16, 15900-15909.

75. Nagels, N.; Geboe, Y.; Pinter, B.; Proft, F. D.; Herrebout, W. A. Tuning the Halogen/Hydrogen Bond Competition: A Spectroscopic and Conceptual DFT Study of Some Model Complexes Involving $\mathrm{CHF}_{2} \mathrm{I}$. Chem. Eur. J. 2014, 20, 8433-8443.

76. Scheiner, S. Sensitivity of Noncovalent Bonds to Intermolecular Separation: Hydrogen, Halogen, Chalcogen, and Pnicogen Bonds. CrystEngComm 2013, 15, 3119-3124.

77. Esrafili, M. D.; Fatehi, P.; Solimannejad, M. Mutual Interplay between Pnicogen Bond and Dihydrogen Bond in $\mathrm{HMH} \cdots \mathrm{HCN} \cdots \mathrm{PH}_{2} \mathrm{X}$ Complexes $(\mathrm{M}=\mathrm{Be}, \mathrm{Mg}, \mathrm{Zn} ; \mathrm{X}=\mathrm{H}, \mathrm{F}, \mathrm{Cl})$. Comput. Theor. Chem. 2014, 1034, 1-6.

78. Adhikari, U.; Scheiner, S. Effects of Carbon Chain Substituent on the P $\cdots$ N Noncovalent Bond. Chem. Phys. Lett. 2012, 536, 30-33.

79. Hauchecorne, D; Herrebout, W. A. Experimental Characterization of $\mathrm{C}-\mathrm{X} \cdots \mathrm{Y}-\mathrm{C}(\mathrm{X}=\mathrm{Br}, \mathrm{I} ; \mathrm{Y}=\mathrm{F}, \mathrm{Cl})$ Halogen-Halogen Bonds. J. Phys. Chem. A 2013, 117, 11548-11557.

80. Adhikari, U.; Scheiner, S. Comparison of $\mathrm{P} \cdots \mathrm{D}(\mathrm{D}=\mathrm{P}, \mathrm{N})$ with Other Noncovalent Bonds in Molecular Aggregates. J. Chem. Phys. 2011, 135, 184306.

81. Scheiner, S. Comparison of $\mathrm{CH} \cdots \mathrm{O}, \mathrm{SH} \cdots \mathrm{O}$, Chalcogen, and Tetrel Bonds Formed by Neutral and Cationic Sulfur-Containing Compounds. J. Phys. Chem. A 2015, 119, 9189-9199.

82. Viger-Gravel, J.; Leclerc, S.; Korobkov, I.; Bryce, D. L. Correlation between ${ }^{13}$ C Chemical Shifts and the Halogen Bonding Environment in a Series of Solid Para-Diiodotetrafluorobenzene Complexes.

CrystEngComm 2013, 15, 3168-3177. 
Table 1. Vibrational stretching and bending frequencies $v$, and intensities I, and NMR chemical shielding (relative to TMS) of fully optimized monomers.

\begin{tabular}{|c|c|c|c|c|c|c|}
\hline & $\mathrm{SMe}_{3}^{+}$ & $\mathrm{SMe}_{2}$ & $\mathrm{NMe}_{4}{ }^{+}$ & $\mathrm{SMe}_{3}{ }^{+}$ & $\mathrm{SMe}_{2}$ & $\mathrm{NMe}_{4}^{+}$ \\
\hline \multicolumn{4}{|c|}{ v, CH stretches, $\mathrm{cm}^{-1}$} & \multicolumn{3}{|c|}{$\mathrm{I}, \mathrm{CH}$ stretches, $\mathrm{km} \mathrm{mol}^{-1}$} \\
\hline asym & 3207.1 & 3171.5 & 3202.8 & 3.95 & 5.52 & 0.08 \\
\hline asym & 3197.2 & 3155.6 & 3199.7 & 5.56 & 10.77 & 0.08 \\
\hline sym & 3081.4 & 3066.4 & 3094.4 & 3.41 & 28.25 & 0.13 \\
\hline \multicolumn{4}{|c|}{$v, \mathrm{CH}$ bends, $\mathrm{cm}^{-1}$} & \multicolumn{3}{|c|}{$\mathrm{I}, \mathrm{CH}$ bends, $\mathrm{km} \mathrm{mol}^{-1}$} \\
\hline scissor & 1431.1 & 1448.8 & 1481.7 & 19.61 & 7.98 & 21.06 \\
\hline scissor & 1425.3 & 1438.0 & 1477.4 & 10.85 & 8.08 & 20.94 \\
\hline umbrella & 1333.2 & 1323.3 & 1447.8 & 1.29 & 2.08 & 4.37 \\
\hline \multicolumn{4}{|c|}{ NMR $\Delta \sigma, \mathrm{ppm}$} & & & \\
\hline $\mathrm{C}$ & -31.30 & -22.11 & -58.64 & & & \\
\hline $\mathrm{H}$ & -3.02 & -1.92 & -3.12 & & & \\
\hline
\end{tabular}


Table 2. Interaction energies for tetrel-bonded and H-bonded geometries of indicated complexes, along with intermolecular distance. Vibrational frequencies and NMR chemical shifts are reported as changes relative to uncomplexed fully optimized monomer.

\begin{tabular}{|c|c|c|c|c|c|c|c|c|c|c|c|c|}
\hline & \multicolumn{2}{|c|}{$\mathrm{SMe}_{3}{ }^{+\cdot \cdot} \mathrm{NH}_{3}$} & \multicolumn{2}{|c|}{$\mathrm{SMe}_{3}{ }^{+\cdot .} \mathrm{OH}_{2}$} & \multicolumn{2}{|c|}{$\mathrm{SMe}_{3}{ }^{+\cdot .} \mathrm{OCH}_{3}^{-}$} & \multicolumn{2}{|c|}{$\mathrm{SMe}_{2} \cdot \mathrm{OH}^{-}$} & \multicolumn{2}{|c|}{$\mathrm{SMe}_{2} \cdot \mathrm{HCOO}^{-}$} & \multicolumn{2}{|c|}{$\mathrm{NMe}_{4}{ }^{+\cdot .} \mathrm{OCHNH}_{2}$} \\
\hline & tetrel & $\mathrm{CH} \cdot \mathrm{O}$ & tetrel & $\begin{array}{l}\mathrm{CH} \cdot \cdot \\
\mathrm{O}\end{array}$ & tetrel & $\mathrm{CH} \cdot \mathrm{O}$ & tetrel & $\mathrm{CH} \cdot \mathrm{O}$ & tetrel & $\mathrm{CH} \cdot \mathrm{O}$ & tetrel & $\mathrm{CH} \cdot \mathrm{O}$ \\
\hline $\begin{array}{l}-\mathrm{E}_{\text {int }}, \\
\mathrm{kcal} / \mathrm{mol}\end{array}$ & 8.16 & 9.99 & 7.69 & 9.59 & 87.69 & 110.51 & 11.69 & 15.42 & 6.85 & 6.79 & 12.84 & 14.72 \\
\hline $\begin{array}{l}\mathrm{R}(\mathrm{C} \cdot \mathrm{N} / \mathrm{O}), \\
\AA\end{array}$ & 2.976 & 3.294 & 2.836 & 3.213 & $2.800^{\mathrm{a}}$ & $2.800^{\mathrm{a}}$ & 2.672 & 2.799 & 2.798 & 3.119 & 2.693 & 3.104 \\
\hline \multicolumn{13}{|c|}{$\mathrm{CH}$ stretches, $\mathrm{cm}^{-1}$} \\
\hline asym & 0.7 & 4.8 & 13.0 & -14.3 & 10.4 & -33.7 & 40.4 & -75.2 & 37.1 & -43.2 & 14.1 & 10.5 \\
\hline asym & 8.9 & -36.6 & 7.2 & -9.0 & 3.7 & -75.0 & 52.5 & -117.2 & 40.0 & -59.9 & 13.2 & -12.7 \\
\hline sym & 4.4 & -63.1 & 11.0 & -13.6 & 9.9 & -290.7 & 48.1 & -987.0 & 33.9 & -94.0 & 11.7 & -7.1 \\
\hline \multicolumn{13}{|c|}{$\mathrm{CH}$ bends, $\mathrm{cm}^{-1}$} \\
\hline asym & -25.4 & 33.4 & -12.8 & 15.2 & -46.8 & 33.3 & -32.4 & 18.8 & -16.8 & 8.5 & -18.2 & 9.2 \\
\hline asym & -19.9 & 20.7 & -13.5 & 10.6 & -47.6 & -0.2 & -29.1 & 16.6 & -17.7 & 3.2 & -17.2 & 4.9 \\
\hline umbrella & -49.6 & 28.3 & -24.6 & 8.4 & -90.7 & 11.9 & -63.0 & 65.3 & -29.7 & 27.4 & -35.5 & 10.5 \\
\hline \multicolumn{13}{|c|}{$\operatorname{NMR} \Delta \sigma, \mathrm{ppm}$} \\
\hline $\mathrm{C}$ & -5.79 & -0.94 & -4.66 & 0.89 & -13.85 & 11.88 & -7.42 & -9.44 & -7.13 & -2.99 & -2.71 & 1.71 \\
\hline $\mathrm{H}$ & -0.32 & -3.71 & -0.09 & -1.79 & -1.08 & -8.57 & -1.37 & -12.75 & -0.64 & -5.30 & -0.49 & -2.72 \\
\hline other $\mathrm{H}$ & -0.34 & 0.21 & -0.20 & 0.35 & -2.30 & 1.81 & -1.29 & 0.67 & -0.84 & 0.29 & -0.32 & 0.40 \\
\hline other $\mathrm{H}$ & -0.39 & 0.37 & -0.54 & -0.04 & -1.43 & 0.05 & -1.28 & 0.71 & -0.73 & 0.39 & -0.48 & 0.32 \\
\hline average $\mathrm{H}$ & -0.35 & -1.04 & -0.28 & -0.50 & -1.60 & -2.23 & -1.31 & -3.79 & -0.74 & -1.54 & -0.43 & -0.67 \\
\hline
\end{tabular}

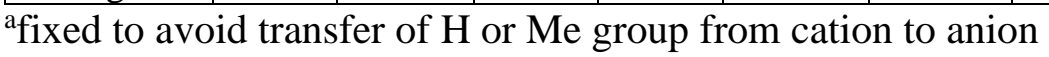


Table 3. Intensities $(\mathrm{km} / \mathrm{mol})$ of vibrational modes

\begin{tabular}{|c|c|c|c|c|c|c|c|c|c|c|c|c|}
\hline & \multicolumn{2}{|c|}{$\mathrm{SMe}_{3}^{+\cdot \cdot \cdot \mathrm{NH}_{3}}$} & \multicolumn{2}{|c|}{ 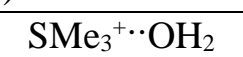 } & \multicolumn{2}{|c|}{ 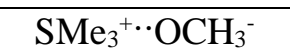 } & \multicolumn{2}{|c|}{$\mathrm{SMe}_{2} \cdot \mathrm{OH}^{-}$} & \multicolumn{2}{|c|}{$\mathrm{SMe}_{2} \cdot \cdot \mathrm{HCOO}^{-}$} & \multicolumn{2}{|c|}{$\mathrm{NMe}_{4}^{+\cdot \cdot \mathrm{OCHNH}_{2}}$} \\
\hline & tetrel & $\mathrm{CH} \cdot \cdot \mathrm{O}$ & tetrel & $\mathrm{CH} \cdot \cdot \mathrm{O}$ & tetrel & $\mathrm{CH} \cdot \cdot \mathrm{O}$ & tetrel & $\mathrm{CH} \cdot \cdot \mathrm{O}$ & tetrel & $\mathrm{CH} \cdot \cdot \mathrm{O}$ & tetrel & $\mathrm{CH} \cdot \cdots \mathrm{O}$ \\
\hline \multicolumn{13}{|c|}{ CH stretches } \\
\hline asym & 5.92 & 3.00 & 2.96 & .33 & 5.21 & 2.73 & 1.48 & 7 & 1.84 & 22.68 & 0.13 & 107.15 \\
\hline asym & 2.71 & 68.33 & 5.09 & 3.70 & 7.39 & 54.86 & 1.66 & 40 & 2.10 & 147.30 & 0.13 & 1.97 \\
\hline sym & 3.73 & 224.22 & 5.77 & 38.88 & 33.21 & 1299.80 & 0.74 & $13.04^{\mathrm{a}}$ & 3.50 & 333.15 & 0.11 & 49.04 \\
\hline \multicolumn{13}{|c|}{$\mathrm{CH}$ bends } \\
\hline asym & 18.08 & 11.90 & 55 & 37 & 16.52 & 13.20 & 7.09 & 1.35 & 6.94 & 5.43 & 18.08 & 21.62 \\
\hline asym & 9.49 & 7.84 & 17.50 & 20.10 & 27.94 & 19.02 & 5.98 & 2.72 & 7.68 & 2.92 & 18.11 & 16.98 \\
\hline umbrel & 1.44 & 3.78 & 1.95 & 0.45 & 5.06 & 4.70 & 1.41 & 8.93 & 1.32 & 17.32 & 8.52 & 2.52 \\
\hline
\end{tabular}

${ }^{a}$ nearly pure $\mathrm{CH}$ stretch

Table 4. Interaction energies for tetrel-bonded and $\mathrm{H}$-bonded geometries of $\mathrm{SMe}_{3}{ }^{+\cdot} \mathrm{NH}_{3}$ at several intermolecular distances $\mathrm{R}(\mathrm{C} \cdot \mathrm{N})$. Vibrational frequencies and NMR chemical shifts are reported as changes relative to uncomplexed fully optimized $\mathrm{SMe}_{3}{ }^{+}$monomer.

\begin{tabular}{|c|c|c|c|c|c|c|c|c|}
\hline & \multicolumn{2}{|c|}{$\mathrm{opt}^{\mathrm{a}}$} & \multicolumn{2}{|c|}{$\mathrm{R}=3.5 \AA$} & \multicolumn{2}{|c|}{$\mathrm{R}=3.8 \AA$} & \multicolumn{2}{|c|}{$\mathrm{R}=4.1 \AA$} \\
\hline & tetrel & $\mathrm{CH} \cdot \mathrm{O}$ & tetrel & $\mathrm{CH} \cdot \cdot \mathrm{O}$ & tetrel & $\mathrm{CH} \cdot \mathrm{O}$ & tetrel & $\mathrm{CH} \cdot \cdot \mathrm{O}$ \\
\hline$-\mathrm{E}_{\text {int }}, \mathrm{kcal} / \mathrm{mol}$ & 8.16 & 9.99 & 7.06 & 9.73 & 6.15 & 8.63 & 5.37 & 7.43 \\
\hline \multicolumn{9}{|c|}{ CH stretches, $\mathrm{cm}^{-1}$} \\
\hline asym & 0.7 & 4.8 & -0.1 & 6.3 & 1.8 & 6.6 & 3.8 & 5.5 \\
\hline asym & 8.9 & -36.6 & 8.1 & -31.9 & 7.9 & -30.2 & 7.5 & -29.5 \\
\hline sym & 4.4 & -63.1 & 5.3 & -49.3 & 7.1 & -41.3 & 7.9 & -36.8 \\
\hline \multicolumn{9}{|c|}{$\mathrm{CH}$ bends, $\mathrm{cm}^{-1}$} \\
\hline asym & -25.4 & 33.4 & -17.1 & 26.0 & -15.0 & 19.0 & -13.4 & 16.1 \\
\hline asym & -19.9 & 20.7 & -14.9 & 18.9 & -10.2 & 17.3 & -8.8 & 15.6 \\
\hline umbrella & -49.6 & 28.3 & -31.7 & 23.3 & -23.5 & 18.8 & -18.3 & 16.2 \\
\hline \multicolumn{9}{|c|}{ NMR $\Delta \sigma, \mathrm{ppm}$} \\
\hline $\mathrm{C}$ & -5.79 & -0.94 & -4.04 & -0.74 & -2.62 & -0.60 & -1.22 & -0.44 \\
\hline $\mathrm{H}$ & -0.32 & -3.71 & -0.19 & -2.57 & -0.12 & -1.60 & -0.09 & -1.03 \\
\hline other $\mathrm{H}$ & -0.34 & 0.21 & -0.20 & 0.12 & -0.14 & 0.02 & -0.11 & -0.04 \\
\hline other $\mathrm{H}$ & -0.39 & 0.37 & -0.16 & 0.27 & -0.08 & 0.19 & -0.03 & 0.13 \\
\hline average $\mathrm{H}$ & -0.35 & -1.04 & -0.18 & -0.73 & -0.11 & -0.46 & -0.07 & -0.31 \\
\hline
\end{tabular}

${ }^{\mathrm{a}}$ optimized $\mathrm{R}(\mathrm{C} \cdot \mathrm{N})$ distances are $2.98 \AA$ for tetrel bond and $3.29 \AA$ for $\mathrm{H}-$ bond. 

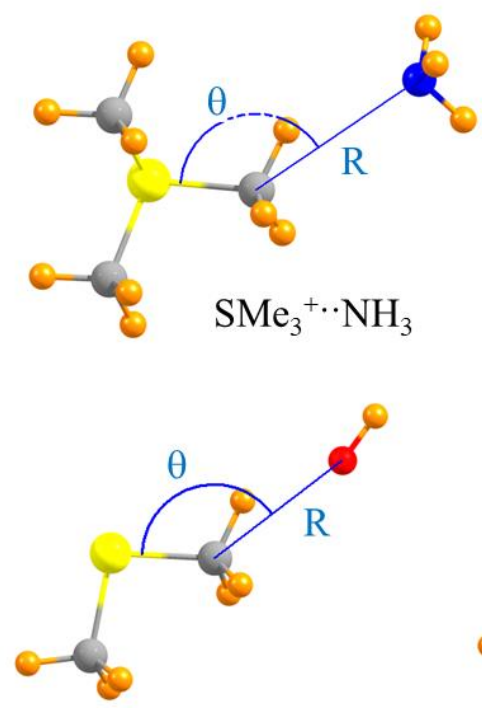

$\mathrm{SMe}_{2} \cdot \mathrm{OH}^{-}$
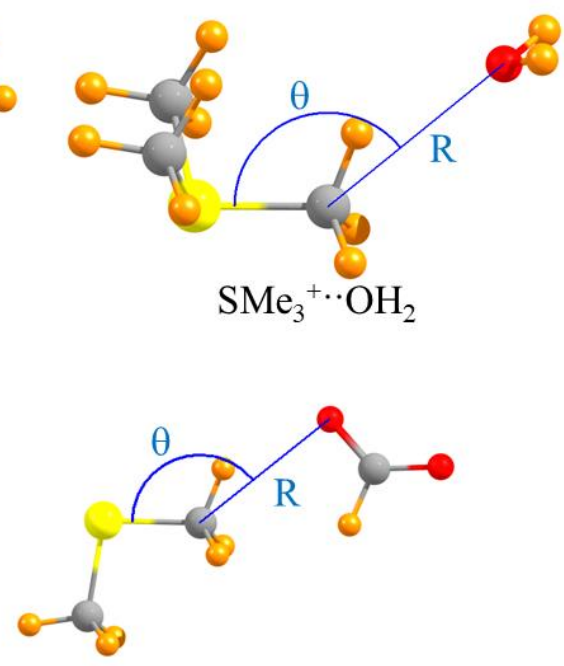

$\mathrm{SMe}_{2} \cdot{ }^{\circ} \mathrm{OCHO}^{-}$
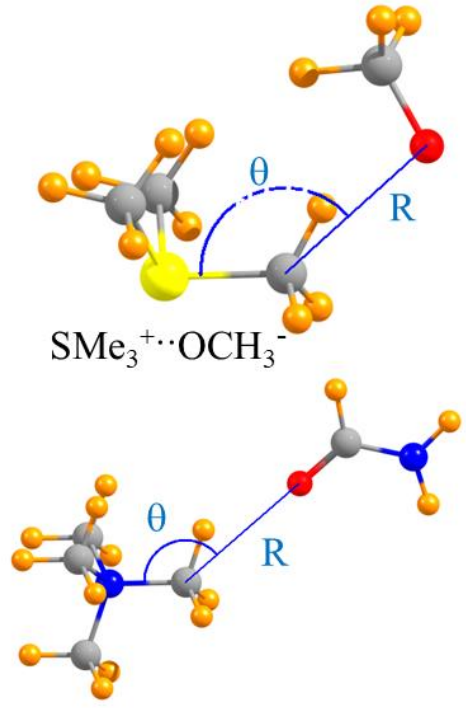

$\mathrm{NMe}_{4}^{+\cdot \cdot} \mathrm{OCHNH}_{2}$

Fig 1. Molecular diagrams of systems examined, defining intermolecular distance $\mathrm{R}$ and angle $\theta$. 

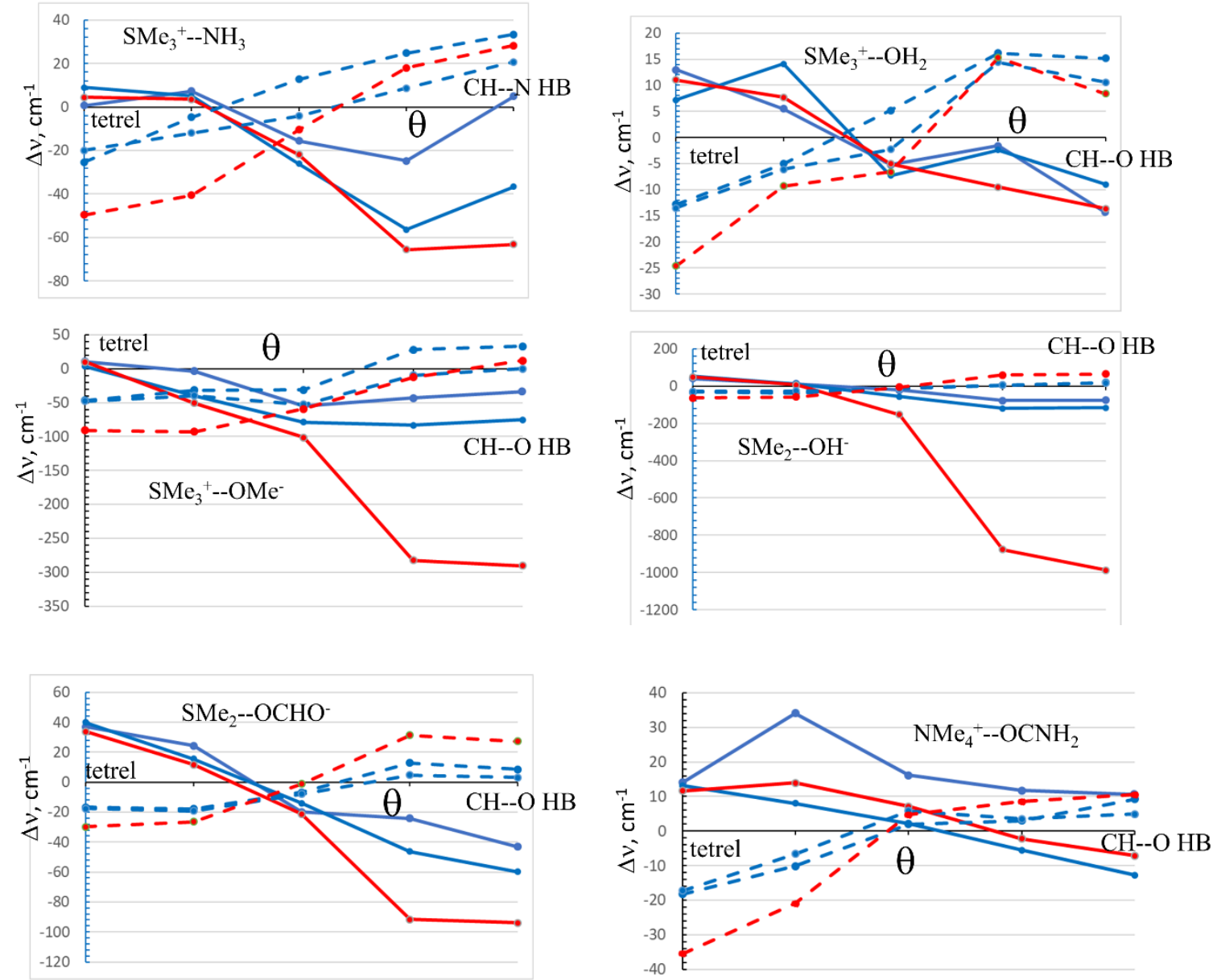

Fig 2. Changes in vibrational frequencies of methyl groups caused by interaction with a nucleophile. Tetrelbonding configuration $\left(\theta=180^{\circ}\right)$ on the left and $\mathrm{CH} \cdot \cdot \mathrm{O} / \mathrm{N} \mathrm{H}$-bond $\left(\theta \sim 110^{\circ}\right)$ on the right. Solid curves refer to stretching modes and bending modes are indicated by broken curves. Blue and red colors respectively represent asymmetric and symmetric motions. 

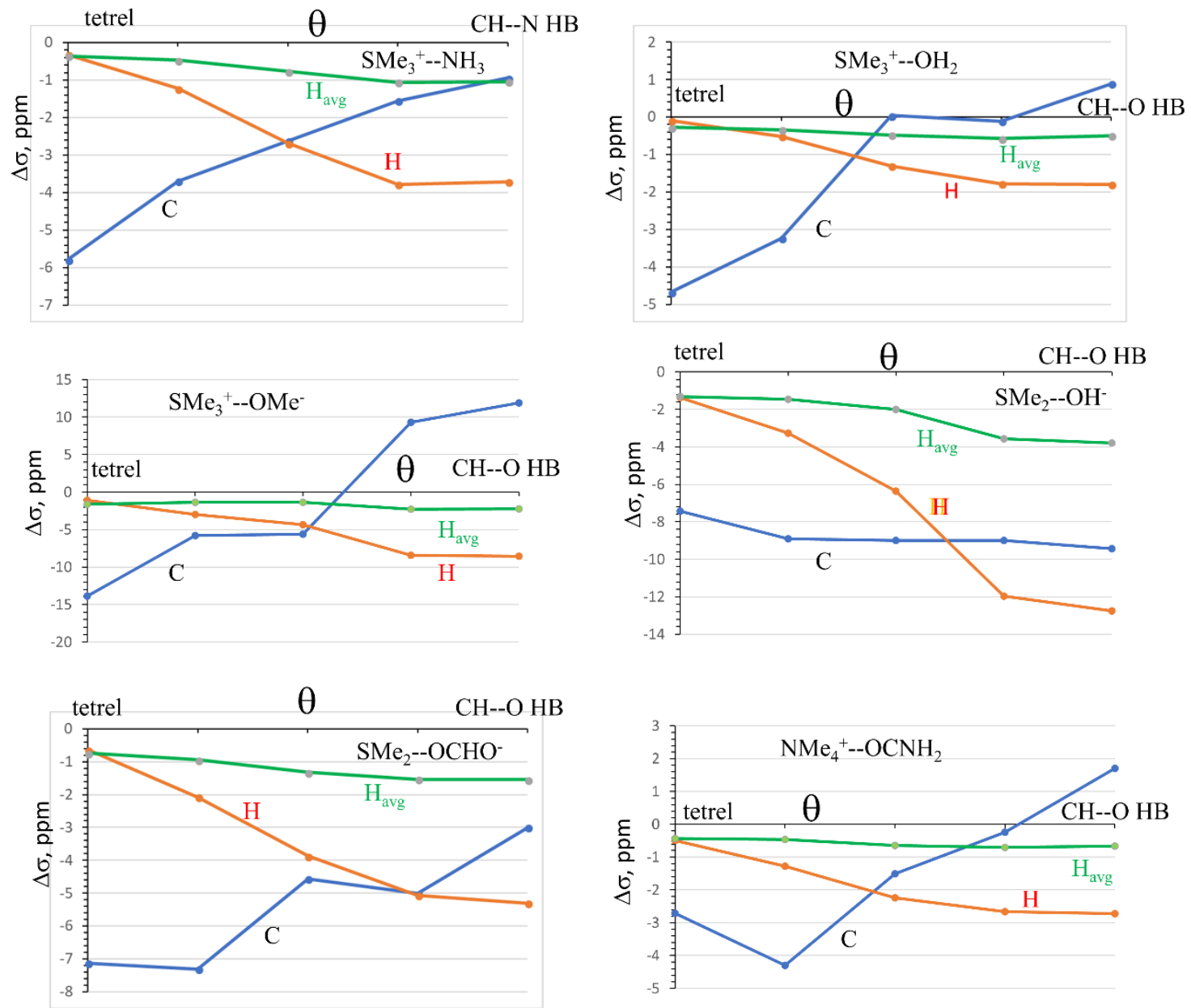

Fig 3. Changes in chemical shielding caused by interaction with a nucleophile. Tetrel-bonding configuration $\left(\theta=180^{\circ}\right)$ on the left and $\mathrm{CH} \cdot \cdot \mathrm{O} / \mathrm{N} \mathrm{H}-$ bond $\left(\theta \sim 110^{\circ}\right)$ on the right. 


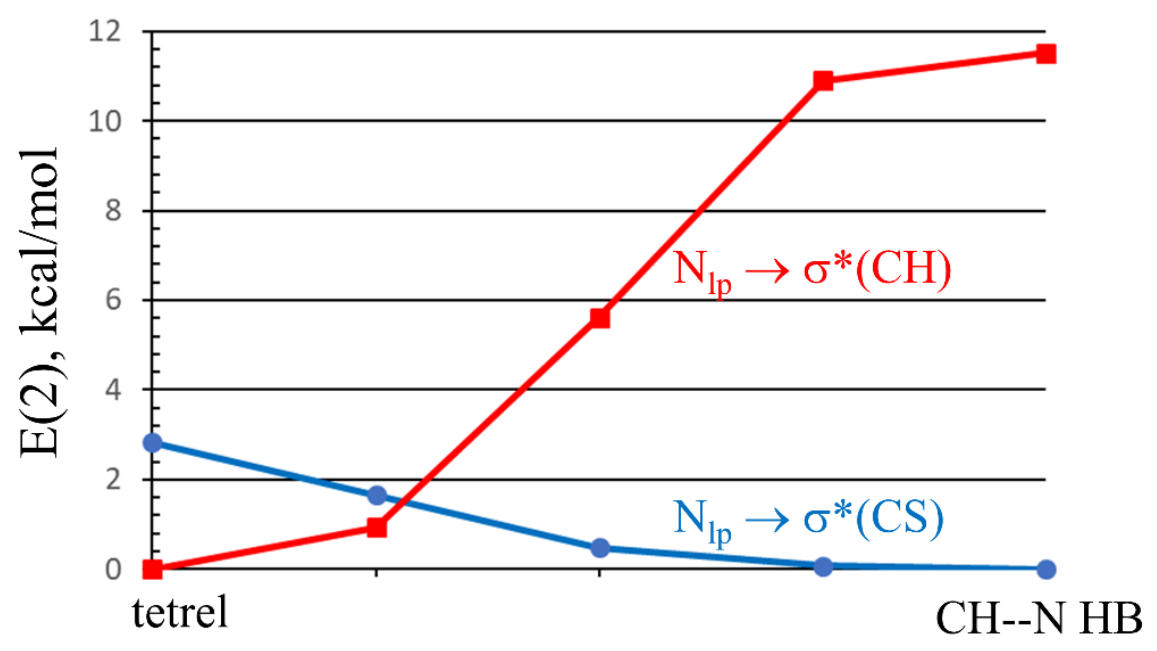

Fig 4. NBO values of $\mathrm{E}(2)$ for charge transfer from $\mathrm{N}$ lone pair to $\sigma^{*}(\mathrm{CS})$ (blue curve) and to $\sigma^{*}(\mathrm{CH})$ red curve antibonding orbitals for $\mathrm{SMe}_{3}{ }^{+\cdot .} \mathrm{NH}_{3}$ system. Tetrel-bonding configuration $\left(\theta=180^{\circ}\right)$ on the left and $\mathrm{CH} \cdot \cdot \mathrm{N}$ H-bond $\left(\theta \sim 110^{\circ}\right)$ on the right. 


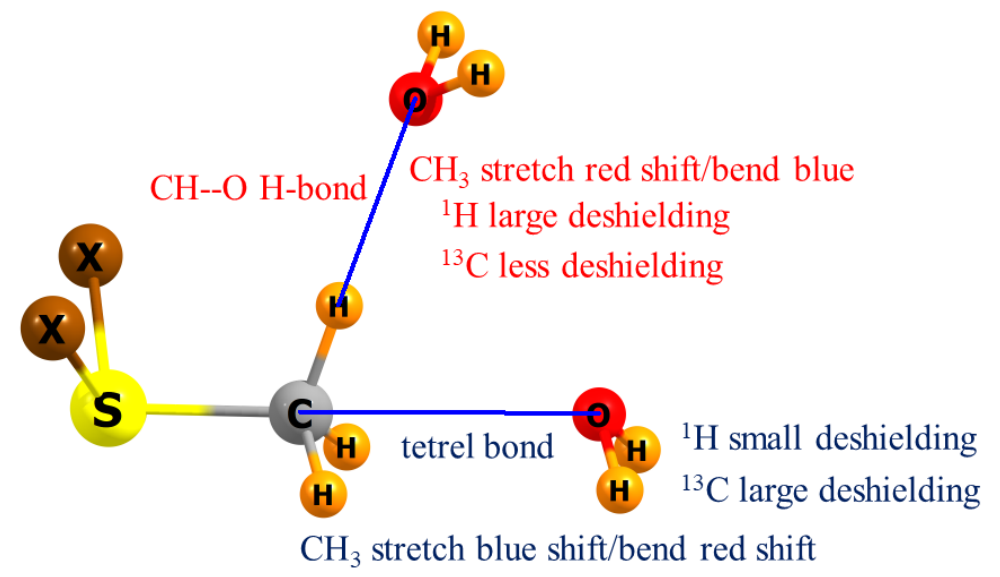

